\title{
Medical Waste Management and Disposal Practices of Health Facilities in Kumbo East and Kumbo West Health Districts
}

\author{
Lanyuy Gillian Dzekashu ${ }^{1,4 a}$, Jane Francis Akoachere ${ }^{2 \#}$, Wilfred Fon Mbacham ${ }^{1,3 * \#}$ \\ ${ }^{1}$ Department of Health Economics, Policy and Management, Catholic University of Cameroon-Bamenda, Cameroon \\ ${ }^{2}$ Department of Microbiology and Parasitology, University of Buea, Cameroon \\ ${ }^{3}$ Pubilic Health Biotechnology, University of Yaounde I, Cameroon \\ ${ }^{4}$ Ministry of Secondary Education, Cameroon

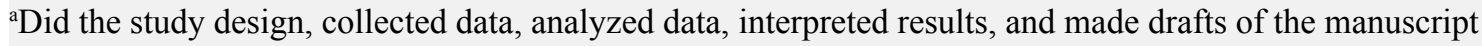 \\ \#Supervised the work, did a critical academic review of all the manuscripts, and approved submission of the final draft
}

*Corresponding author: Wilfred Fon Mbacham, Department of Health Economics, Policy and Management Catholic University of Cameroon-Bamenda, Tel: +237677579180; E-mail-wfmbacham@yahoo.com

\begin{abstract}
Background: The provision of healthcare generates waste which can be detrimental to health and the environment. Management of healthcare waste is still a challenge in developing countries as practices, capacities and policies on waste disposal are grossly inadequate and require intensification. With the growing trend of biomedical services in Kumbo Cameroon, we investigated the medical waste management practices in this area, to generate data that could guide policy in planning for an effective and sustainable waste management program.

Method: A qualitative cross sectional study was conducted in 30 of the 52 health facilities in study area. Participating facilities were selected by convenience sampling and personnel by random sampling. Data was collected using questionnaires, interviews and direct field observations. The Chi Square test was used together with percentages, and results analyzed using SPSS V 17.0. P-values $<0.05$ were considered significant. Results: Participants aware of the existence of a national policy guide on medical waste management were mostly administrators (66.7\%). Only $2(6.6 \%)$ health facilities had a copy of this document. None of the participating facilities kept records of their medical waste management practices. All participants were aware of the health risk of healthcare waste. Use of Personal Protective Equipment (PPE) varied among participants and was highest with Employed Waste Handlers (EWH) (100\%) and laboratory technicians $(69 \%)$. Gloves were the most commonly used PPE. Most of the EWH (55.6\%) used examination gloves which was inappropriate. Not all participants segregated or disinfected waste. Waste bins were not color-coded and all facilities had appropriate safety boxes for sharps. In $86.7 \%$ of health facilities, waste disposal was by burning in pits located within $400 \mathrm{~m}$ away from the facility. Most of these pits were not protected from scavengers. Only 4 facilities had incinerators and all did not meet the required standards. Even after segregation at the point of generation, wastes were mixed at the point of final disposal.

Conclusion: Waste management practices in study site did not meet standard practices. There is an urgent need for proper medical waste management in Kumbo East and Kumbo West to minimize threats to human health and the environment. Regular supervision and enforcement of policy on medical waste management is paramount.
\end{abstract}

Received date: July 04, 2016

Accepted date: October 31, 2016

Published date: November 02, 2016

Citation: Mbacham, W.F., et al. Medical Waste Management and Disposal Practices of Health Facilities in Kumbo East and Kumbo West Health Districts. (2016) J Environ Health Sci 2(6): 1- 9.

DOI: $10.15436 / 2378-6841.16 .990$

Keywords: Medical waste; Medical waste management; Medical waste disposal; Kumbo

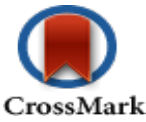

List of abbreviations: EWH: Employed Waste Handler; PPE: Personal Protective Equipment; WHO: World Health Organization; NPG: National Policy Guideline; CMA: Centre Medical d'Arrondisements; OSHA: Occupational Safety and Health Administration 


\section{Introduction and Background}

Medical care is vital for life and health, but waste generated from medical activities has become a serious concern because of its composition. It has a high potential of carrying micro-organisms that can infect individuals exposed to it, as well as the community at large if it is not properly disposed (Babanyara, Y.Y., et al. 2013). Medical waste is the second most hazardous waste after radioactive waste. Being hazardous and infectious, medical waste also poses serious threats to public and environmental health as it may pollute air and contaminate soil and water sources. Thus to protect human and environmental health, healthcare waste requires specific treatment and management prior to its final disposal. Enormous effort is needed to establish the provision of effective and universal healthcare and with it the safe and effective disposal of clinical waste. The last decade has witnessed an increase in the number of health care facilities not only as a result of demographic development but mainly due to aid from international commitment to eradicate and control many infectious diseases. This has led to a concomitant increase in medical waste generated (Doumtsop, T.J.G. 2014). Efforts to manage such wastes have differed between countries, the worse scenario being in developing countries where such wastes are handled haphazardly (Pruthvish, S., et al 1999, Harhay, M.O., et al 2009, Walkinshaw, E. 2011) with no systematic management of healthcare waste. This is because in these countries, resources for health care delivery are often very limited making it difficult for healthcare waste management to be given the priority it deserves. In many developing countries, regulations governing safe disposal of healthcare waste is either lacking or poorly enforced. In these countries, poor clinical waste management, especially inefficient segregation, treatment and disposal methods threaten the environment, occupational and public health and increase the potential for the transmission of blood borne pathogens (Babanyara, Y.Y., et al. 2013, Solberg, K.E. 2009). An assessment conducted by World Health Organization (WHO) revealed that in twenty two developing countries the proportion of healthcare facilities that do not practice proper healthcare waste management ranges from $18 \%$ to $64 \%$ (WHO 2004). In the African continent, solid medical waste management in most countries is substandard. In a recent review of solid medical waste management in Africa (Udofia, E.A. 2015), only $30 \%$ of countries met half of WHO's recommendations on medical waste management (Chartier, Y., et al 2014), with the greatest compliance recorded on daily collection of waste from points of generation $(100 \%)$. In addition to the fact that waste is never segregated and poorly handled in these countries, uncontrolled and sub-standard burning is widely practiced creating additional environmental problems including emission of toxic air pollutants (particularly dioxin) and heavy metals which might be present in gaseous and solid by-products (Pruss, A.1999). Sound management of medical waste is highly necessary to protect human and environmental health. This involves reducing the generation of hazardous waste, strictly controlling the storage, transport, treatment, reuse, recycling, recovery and final disposal of wastes (UNEP 2000). With the growing concern on medical waste management, some developing countries have recently implemented interventions that have improved their waste management practices (Awodele, O. 2016, Kumar, R. 2015, Tabash, M.I. et al. 2016).
Although there is very limited information on health care waste management in Cameroon, few studies conducted report medical waste management as a challenge in both primary and tertiary care facilities (Doumtsop, T.J.G. 2014). Because resources allocated for healthcare are limited, health care waste management has received less attention and priority than it deserves. Most healthcare facilities lack an incinerator and in some it is broken down and non functional. Waste is burnt in pits situated within the facility. Burning in waste pits releases toxic gases into the air that could endanger the ecosystem (Manga, V.E. 2008, Mochungong, P.I. 2010). In the Northwest region of Cameroon, poor waste management practices observed in some health care facilities has been attributed to lack of sufficient awareness on environmental and public health impacts of poor clinical waste disposal (Mochungong, P.I, 2010) and most health workers were not aware of the existence of policy-national or international- on safe clinical waste management. Another study by Muluken, A. 2013, reported that the working conditions of waste pickers in health facilities are precarious and this endangers not only their health but also that of their families. Although resources are scarce in Cameroon like in most developing countries, there is need to prioritize medical waste management to prevent future use of scare resources to treat health related problems arising from poor medical waste management. Therefore studies on waste management practices are highly necessary to inform policy so that appropriate measure can be taken to ensure safe management and disposal.

Kumbo Municipality in the North West region of Cameroon has experienced a rapid increase in the number of healthcare facilities as well as the types of health care services rendered in the last few years, resulting in an increase in the amount and diversity of waste generated from these facilities. Due to the growing trend of biomedical services in Kumbo, there is need for a comprehensive evaluation of medical waste management and disposal practices in the area, in order to inform policy on the planning for an effective and sustainable waste management program.

\section{Methods}

\section{Study area}

This study was conducted in Kumbo East and Kumbo West health districts in the North West region of Cameroon. Kumbo, the second largest town in North West Cameroon and capital of Bui Division is located $110 \mathrm{~km}$ away from Bamenda, capital city of the North West region. The town of Kumbo has a population of over 100,000 inhabitants with a female dominance of $52 \%$. It shares boundaries with Nkum-Mbam in the North, Mbiame in the East, Oku-Noni in the West and Dzekwa in the South. It enjoys a tropical climate common to most parts of Cameroon with two seasons: the dry and rainy seasons. Its geographical coordinates in decimal degrees (WGS84) are: Latitude 6.200 and Longitude 10.667.

With regards to health care delivery, Kumbo has two health districts: Kumbo East and Kumbo West, with 30 health areas and a total of 52 health facilities. These health facilities comprise public (state-owned $=25$ ), lay private (owned by individual $=5$ ), community-owned (2) and confessional (owned by religious body $=20$ ). Kumbo East has 20 health areas with 34 health facilities while there are 10 health areas in Kumbo West 
with 18 health facilities.

There are two main hospitals in Kumbo both of which have training schools for health personnel, and a range of departments offering services like: general consultation, eye care, dental care, surgical services, X-ray/ultrasound, pharmaceutical services, laboratory services, pediatric services, gynecological, obstetric services, family planning, tuberculosis treatment units, vaccination and antenatal care, malaria prevention among others. One of the hospitals in addition has the only Cardio-Surgical Centre in Central/West Africa which offers cardiac surgery, diagnostic and interventional catheterization, coronary angiography, diagnostic coronarography, pace maker double and single chamber since 2009. Figure 1

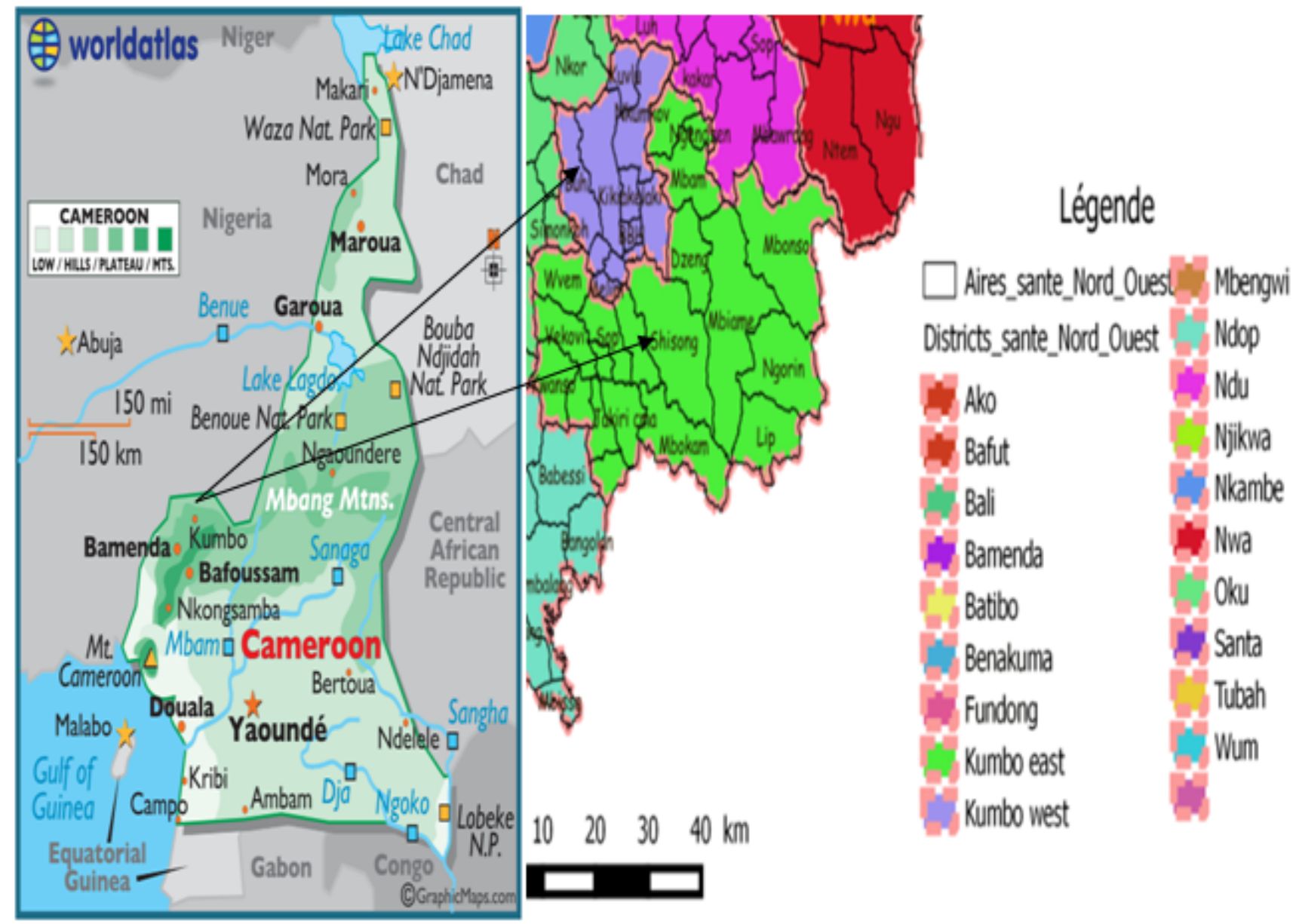

Figure 1: Map of study area.

\section{Study design}

A cross sectional study with convenience sampling used to select health facilities for the study was conducted from September to December 2013. The choice of sampling method was to ensure that the two major hospitals in study area; one in Kumbo West and another in Kumbo East were included due to the broad range of healthcare services they offer. From a total of 52 health facilities in study area, 16 were selected from Kumbo East and 14 from Kumbo West. If a chosen health area had all four categories (public, confessional, lay private, community-owned) of health facilities, all were selected in order to have a category representation. A minimum of 2 health facilities were selected from each selected health area. A total of 14 public, 8 confessional, 6 lay private, and 2 community-owned health facilities were selected. Data on waste management practices was collected by questionnaires, field observations and interviews with randomly selected health personnel who were available at the time of the study.

\section{Study population}

All categories of staff in selected healthcare institutions such as administrators, doctors, nurses, laboratory technicians, pharmacy attendants and waste handlers were targeted. Personnel from all departments were sampled so as to have a broad range of the medical waste types generated and management practices. Healthcare facilities in Kumbo East and Kumbo West health districts and their personnel directly or' indirectly involved in medical waste management and disposal that gave consent to participate were recruited for the study.

\section{Characteristics of study participants}

A total of 260 participants were involved in this study. Nurses made up the highest number of participants 154 (59.2\%), followed by laboratory technicians $34(13.1 \%)$ and Employed Waste Handlers (EWH) 27 (10.4\%), while administrators 6 $(2.3 \%)$ were the least. Participation by gender reflected a male dominance of $58.8 \%$ (Table 1). 
Table 1: Characteristics of study participants.

\begin{tabular}{|c|c|c|}
\hline Characteristic & Number & Percentage \\
\hline \multicolumn{3}{|l|}{ a. Gender } \\
\hline Male & 153 & 58.8 \\
\hline Female & 107 & 41.2 \\
\hline Total & 260 & 100 \\
\hline \multicolumn{3}{|l|}{ b. Profession } \\
\hline Nurse & 154 & 59.2 \\
\hline Pharmacy Attendant & 29 & 11.2 \\
\hline Doctor & 10 & 3.8 \\
\hline Laboratory Technician & 34 & 13.1 \\
\hline Administrator & 6 & 2.3 \\
\hline Employed Waste Handler (EWH) & 27 & 10.4 \\
\hline \multicolumn{3}{|c|}{ c. Waste Management included in Curriculum during training } \\
\hline Nurse & 105 & 68.2 \\
\hline Pharmacy Attendant & 19 & 65.5 \\
\hline Doctor & 5 & 50 \\
\hline Laboratory Technician & 32 & 94.1 \\
\hline Administrator & 4 & 66.7 \\
\hline Employed Waste Handler (EWH) & 13 & 48.1 \\
\hline \multicolumn{3}{|c|}{ d. Attended seminar/workshop on waste management } \\
\hline Nurse & 58 & 37.7 \\
\hline Pharmacy Attendant & 8 & 27.6 \\
\hline Doctor & 2 & 20 \\
\hline Laboratory Technician & 8 & 23.5 \\
\hline Administrator & 4 & 66.7 \\
\hline Employed Waste Handler (EWH) & 13 & 48.1 \\
\hline
\end{tabular}

\section{Data Collection}

The instruments used in generating primary data included questionnaires administered to health personnel. Structured interview forms were used to assess medical waste management practices of health facilities. Observations during field visits were guided by an observation checklist in order that key aspects to be evaluated could be noted down in a systematic manner.

Data was analyzed using SPSS software package (V 17.0). The Chi square test and percentages were used and P-value $<0.05$ was considered significant.

\section{Results}

\section{Personnel knowledge on medical waste management}

(1) Awareness on the existence of, and availability of a National Policy Guideline

Among our study participants, those aware of the existence of a National Policy Guide (NPG) on medical waste management were mainly administrators $(66.7 \%)$ and nurses $(61 \%)$ and the least were pharmacy attendants $(6.9 \%)$ (Figure 2$)$. There was no significant difference in awareness on the existence of a NPG with respect to category of personnel (P-value $=0.134$ ). Most of those aware of the existence of a NPG were from Community health facilities $(66.7 \%)$, followed by personnel from Confessional health facilities $(45.1 \%)$ while the least were from public health facilities.

Only 2/30 (6.67\%) health facilities (all public), had a copy of the National Policy Guideline on medical waste management to guide their medical waste management practices. One of the main hospitals had an internal waste management manual designed by its authorities. None of the participating health facilities kept records of its medical waste management practices. Among our participants, those who had aspects of waste management included in their curriculum during the period of their training were mostly laboratory technicians $(94.1 \%)$, followed by nurses $(68.2 \%)$ while the least were EWH (48.1\%) (Table $1)$. The difference was significant $(\mathrm{P}=0.024)$. Some personnel attended seminars/workshops on waste management and these were mainly administrators (66.7\%), followed by EWH (48.1\%) while the least were doctors $(20 \%)$ (Table 1$)$. The difference was not significant $(\mathrm{P}=0.035)$.

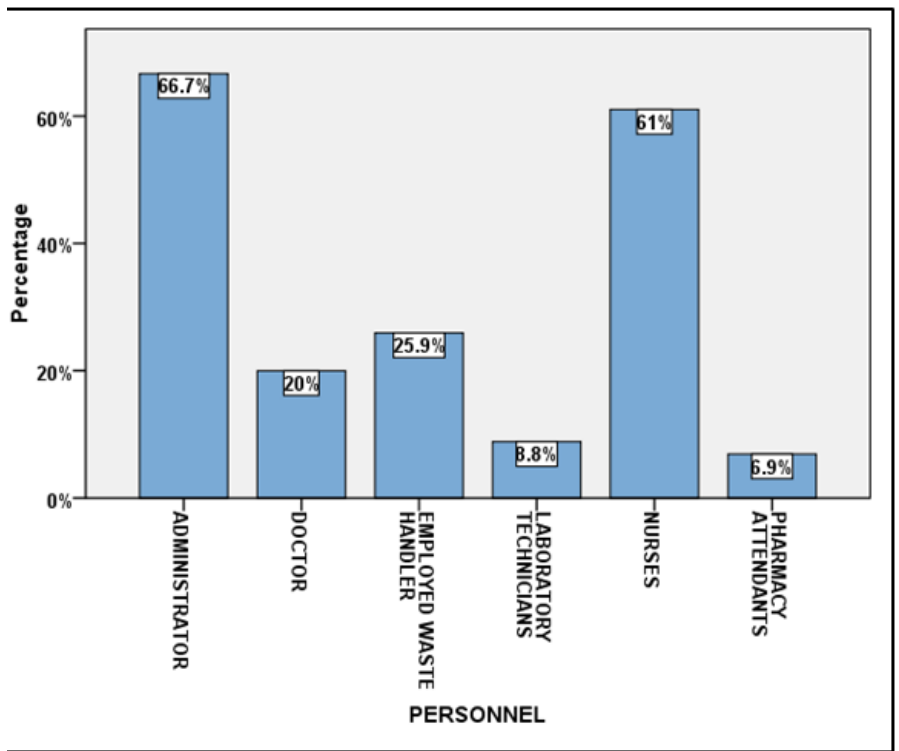

Figure 2: Awareness on the existence of a National Policy Guideline on Medical Waste Management.

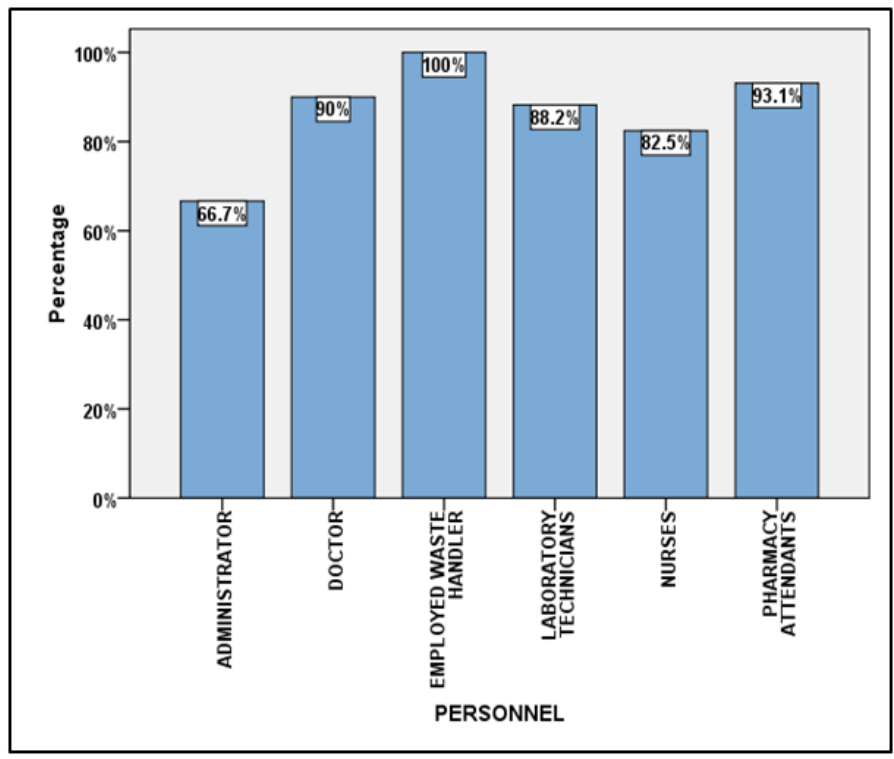

Figure 3: Opinion on Employed Waste handlers at highest risk of exposure to infection from medical waste. 
(2) Opinion of waste handlers on exposure to risk of infection

All health personnel $(260 / 260,100 \%)$ were aware that medical waste is risky to public health. Overall, only $86.2 \%$ considered EWH more exposed to infection from healthcare waste compared to other categories of health personnel. With regard to personnel's opinion, all employed waste handlers (100\%) noted they were more at risk of infection. This was followed by pharmacy attendants $(93.1 \%)$ while the least were administrators $(66.7 \%)$ (Figure 3$)$. The difference was not significant $(\mathrm{P}=$ $0.082)$.

\section{(3) Waste generated from healthcare facilities}

Waste generated from health facilities was extremely heterogeneous comprising pathological waste, pharmaceutical waste, radioactive waste, chemical waste, sharps, infectious and domestic waste (Table 2). Apart from radioactive waste and waste from surgical departments generated by the two main hospitals and some Centre Medical d'Arrondisements (CMAs) due to a broader range of their services, medical waste commonly generated in all healthcare facilities included; used syringes, gloves, wound dressings, empty drip sets, placenta, empty vials, and empty drug containers (plastics and cartons).

Table 2: Waste generated from Health Facilities of Kumbo East and Kumbo West.

\begin{tabular}{|l|l|}
\hline WASTE CATEGORY & TYPES \\
\hline Pathological waste & $\begin{array}{l}\text { Foetuses, placenta, human tissues, body } \\
\text { fluids, faeces, urine, sputum, vomit. }\end{array}$ \\
\hline Pharmaceutical waste & $\begin{array}{l}\text { Expired drugs, empty vials, empty drug } \\
\text { containers (bottles/cartons). }\end{array}$ \\
\hline Radioactive waste & $\begin{array}{l}\text { Ampoules, damaged films, absorbent pa- } \\
\text { per, liquids from radiotherapy. }\end{array}$ \\
\hline Chemical waste & $\begin{array}{l}\text { Batteries, laboratory reagents, stocks dis- } \\
\text { infectants, expired and/or broken ther- } \\
\text { mometers. }\end{array}$ \\
\hline Sharps & $\begin{array}{l}\text { Needles, syringes, infusion sets, scalpels, } \\
\text { pipettes, knives, blades, broken bottles. }\end{array}$ \\
\hline Infectious waste & $\begin{array}{l}\text { Sputum, Vaginal Smear (VS) swaps, used } \\
\text { cotton, gloves, specimen containers, test } \\
\text { strips, soiled gauze, bandages, wound } \\
\text { dressings, agar from culture samples, cul- } \\
\text { ture plates, HIV strips. }\end{array}$ \\
\hline Domestic waste & $\begin{array}{l}\text { Papers, remains of food, other organic } \\
\text { wastes. }\end{array}$ \\
\hline
\end{tabular}

\section{4) Waste management and infection prevention practices}

The use of personal protective equipment varied among personnel, with the highest level of use (100\%) observed among EWH and laboratory technicians while the lowest $(69 \%)$ was with pharmacy attendants (Table 3 ). There was no significant difference in the use of PPE among personnel (P-value $=0.364)$. Gloves $(100 \%)$ were the most common form of PPE used by waste handlers, followed by aprons $(85.2 \%)$ and boots $(55.6 \%)$ None of the waste handlers used face mask while only $48.1 \%$ used nose mask. On further investigation, we realized that the majority of them used examination gloves (55.6\%) while only $44.4 \%$ used utility gloves. With vaccination being another form of protection from certain infectious diseases, we investigated if healthcare workers had been vaccinated against some infections they are exposed to as a result of the nature of their job. Vaccina- tion was against three types of infections: tetanus (63\%), meningitis $(51.9 \%)$ and hepatitis B (29.6\%) (Table 3). These vaccines were received mostly during immunization campaigns. About $80 \%$ of medical personnel had been vaccinated against at least one of the above mentioned diseases. There was a significant difference in the number of participants that had been vaccinated $(\mathrm{X} 2=9.792$, P-value $<0.05)$.

Table 3: Waste Management and Infection Prevention Practices.

\begin{tabular}{|c|c|c|}
\hline \multirow{2}{*}{ Waste Management Practice } & \multicolumn{2}{|c|}{ Response } \\
\hline & Yes $\quad(\%)$ & No $(\%)$ \\
\hline \multicolumn{3}{|l|}{ Do you use PPE } \\
\hline Doctors & 90 & 10 \\
\hline Employed Waste Handlers & 100 & 0 \\
\hline Laboratory Technicians & 100 & 0 \\
\hline Nurses & 98.1 & 1.9 \\
\hline Pharmacy Attendants & 69 & 31 \\
\hline Total & 91.4 & 8.6 \\
\hline \multicolumn{3}{|l|}{ Disinfection of Waste } \\
\hline Doctors & 20 & 80 \\
\hline Lab Technicians & 67.6 & 32.4 \\
\hline Nurses & 26.6 & 73.4 \\
\hline Total & 38.1 & 61.9 \\
\hline \multicolumn{3}{|l|}{ Do you segregate Waste } \\
\hline Doctors & 80 & 20 \\
\hline Employed Waste Handlers & 100 & 0 \\
\hline Lab Technicians & 88.2 & 11.8 \\
\hline Nurses & 81.8 & 18.2 \\
\hline Pharmacy Attendants & 0 & 100 \\
\hline Total & 70 & 30 \\
\hline \multicolumn{3}{|c|}{ Vaccination among employed waste handlers } \\
\hline Hepatitis B & 29.6 & 70.4 \\
\hline Tetanus & 63 & 37 \\
\hline Meningitis & 51.9 & 48.1 \\
\hline Total & 48.2 & 51.8 \\
\hline \multicolumn{3}{|c|}{ Injuries sustained from infected objects } \\
\hline Lab Technicians & 23.5 & 76.5 \\
\hline Doctors & 11 & 89 \\
\hline Employed Waste Handlers & 11 & 89 \\
\hline Total & 14.55 & 85.45 \\
\hline
\end{tabular}

We investigated if personnel who generate infectious waste (doctors, nurses and lab technicians) disinfect such waste prior to disposal. Disinfection was practiced mainly by laboratory technicians $(67.6 \%)$ and least by doctors $(20 \%)$ (Table 3$)$. The difference among these categories of staff was significant $(\mathrm{P}=0.0359)$. Disinfection of infectious waste was widely practiced by personnel from lay private facilities $(56.3 \%)$, followed by those from public facilities $(27.1 \%)$ but was not conducted in community health facilities. There was no significant difference in this practice with regards to the type of health facility $(\mathrm{P}=$ $0.061)$.

Segregation of waste generated prior to disposal was practiced by all EWH (100\%) (Table 3). This was followed by laboratory technicians $(88.2 \%)$. Segregation was not practiced 
by pharmacy attendants $(0 \%)$. There was a significant difference between personnel who segregated waste and those who did not $(\mathrm{P}=0.006)$. Segregation of waste was practiced mainly by staff of confessional health facilities $(85 \%)$, followed by public facilities (52.1\%) However, this practice was absent in community health facilities $(0 \%)$.

All health facilities had waste bins (Figure. 4) for discarding waste. Only $80 \%$ of them had lids and they were not color coded. None of the participating health facilities lined waste bins with plastic bags or biohazard bags during the study period. However, in one of the main hospitals it was reported that plastic bags were used when available. The use of safety boxes for disposal of sharps was practiced in all health facilities.
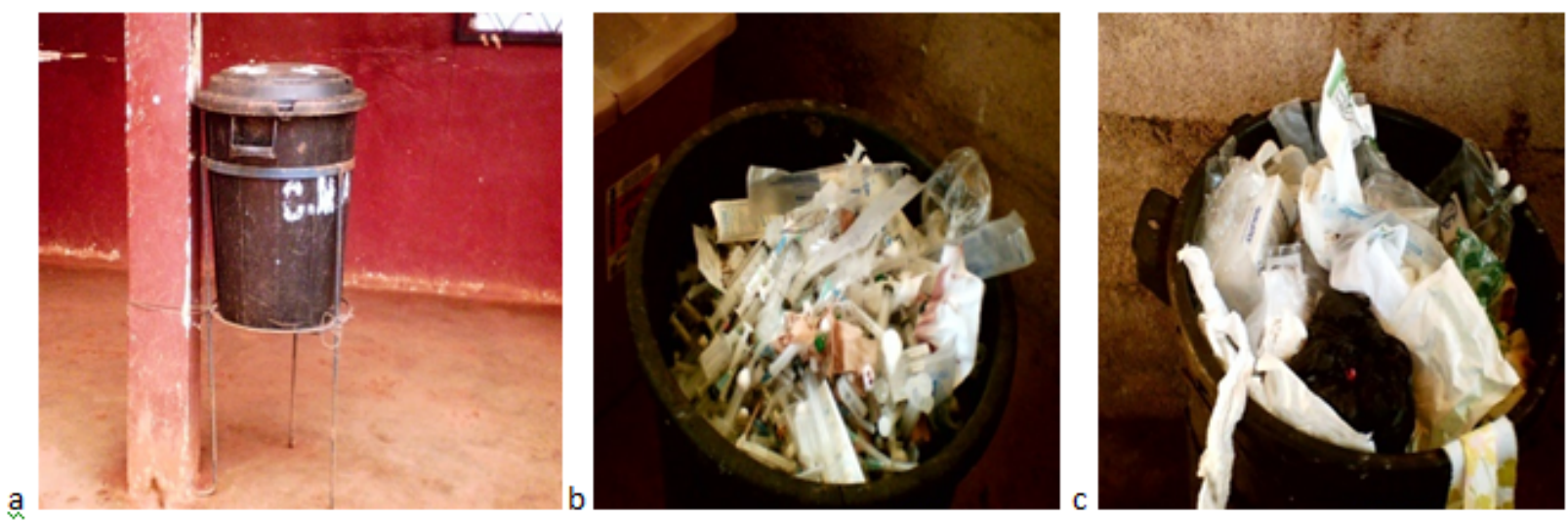

Figure 4: Waste storage in health facilities (a) Waste bin with lid (b and c) unlined waste bins without lids.

\section{(5) Transportation and final disposal of healthcare waste}

Transportation of medical waste from point of generation to final waste disposal site was mostly done by hand-lifting $(96.70 \%)$. Use of trolleys was seldom and observed only in one health facility $(3.33 \%)$.

All health facilities had a permanent site for the disposal of its medical waste. Only $4(13.33 \%)$ health facilities used incinerators. The rest (86.67\%) had excavated pits for dumping waste and ash after burning (Figure 5). Distance of waste disposal sites from health facilities ranged between $5 \mathrm{~m}-400 \mathrm{~m}( \pm 54.57 \mathrm{~m})$. Also, observations showed that $9(30 \%)$ had their disposal sites located $0-10 \mathrm{~m}$ from the premises. Only 1 had its waste disposal site located about 400m away. In addition, most of the health facilities $(73.3 \%)$ did not protect their waste pit from scavengers (Figure 5). Thirty-five (13.5\%) respondents reported human visits (scavengers) while 52 (20\%) reported animal visits to these dump sites. Waste disposal was mainly by EWH in $22 / 30$ ( $73.3 \%$ ) health facilities. However, in facilities that did not employ a waste handler, other personnel such as nurses, doctors and night watch men were involved in waste handling.

Figure 5: Final Waste disposal sites observed in study site: (a) Constructed and fixed Incinerator (b) Mobile incinerator (c \& d) Unprotected Medical Waste pits (e) Protected Medical Waste pit. 


\section{Discussion}

Healthcare waste management is still presenting a series of challenges in developing countries because it has been given little attention. In Cameroon, medical waste management is a serious concern and therefore there is need for an evaluation of current management practices to enable planning, for better management of medical waste.

In addition to studying the waste management practices, we assessed participants' knowledge on aspects related to waste management such the existence of a NPG on waste management and risk of exposure to infection from medical waste. We also investigated if they have ever received training on medical waste management. Only $68.5 \%$ of our participants had medical waste management in their curriculum during their training with laboratory technicians $(94.1 \%)$ being the highest and the least were EWH (48.1\%). Most of our participants received training compared to health care workers in Northwest Ethiopia (Muluken, A. 2013). With regards to in-service training on medical waste management through seminars or workshop, only 35.8\% participated. This low percentage could be due to limited budgetary allocation which does not permit organization of such events. A recent study by Kumar et al. suggested intensive healthcare waste management training as an effective intervention for improving knowledge, attitudes and practices among healthcare workers regarding healthcare waste management. Other studies Kumar, et al 2016, Abah, S.O. 2011 have also indicated regular training of health care workers on waste management to have a great role on their practices on waste management. There is an urgent need for training of healthcare workers on waste management in our study site to improve their practices. All participants were aware of public health risks of medical waste and all the EWH were aware they were at risk of infection.

Contrary to Ramokate and Basu who reported $46 \%$ of participants being aware of the existence of manual on safe management of medical waste, only $43.1 \%$ of participants were aware of the existence of NPG on medical waste management with the highest level of awareness being observed among administrators $(66.7 \%)$ ). Our level of awareness was higher than the $20.8 \%$ reported by Muluken et al and Mochungong et al reported similar findings in the Northwest region of Cameroon. Only $6.6 \%$ of health facilities had a copy of the guide and one facility had a waste management guide designed by its authorities. None of the facilities kept record of its waste management practices. In a similar study in South Africa, accessibility of medical waste management documents was $91 \%$. We associate the low accessibility recorded in our study to poor supervision and enforcement by the responsible authorities.

Waste generated in healthcare facilities was extremely heterogeneous in composition (Table 2) as has been reported in similar studies elsewhere (Hassan, M.M., et al 2008, Debere, M.K., et al 2011) thus creating more challenges in its management. Segregation of waste at source reduces the management and cost of treatment in addition to public health risks and environmental pollution. Overall, $70 \%$ of study participants segregated waste. Our findings contradict the report of Mochungong et al. in which segregation was observed in all hospitals studied in the North West region of Cameroon. The difference could be due to the fact that our study involved more health facilities than studied by Mochungong et al. Segregation of waste was prac- ticed by all EWH (100\%), followed by laboratory technicians $(88.2 \%)$. No pharmacy attendant segregated waste. Segregation was practiced mainly by staff of confessional facilities and was absent among staff of community health facilities.

Disinfection of infectious waste was practiced only by $38.1 \%$ of participants with this practice observed mainly among laboratory technicians $(67.6 \%)$. This could be due to the fact that most laboratory technicians had waste management included in their curriculum during their period of training. As with segregation, none of the community health facilities disinfected their waste. In a recent study in Ethiopia (Debere, M.K., et al 2011) neither waste segregation nor disinfection was reported. At the point of generation, the waste was discarded in plastic bins placed outside the wards and only $80 \%$ of them had lids. These bins were not lined with biohazard bags and neither were they color-coded. However, one hospital reported using biohazard bags when they are available. Bio-hazards signs were not seen on waste bins, although in one of the major hospitals instructive posters showing the type of waste to be discarded in each of the waste bins were fastened to the bin thus acting as a major step towards an effective healthcare waste segregation. There was also adequate provision and use of safety boxes for sharps in all health facilities.

The highest level of use of PPE was observed with EWH (100\%) followed by laboratory technicians (69\%), with gloves being the most common PPE used. The gloves used by EWH were mostly examination gloves which are inappropriate, as it could not only tear easily exposing them to infection but could not offer protection against injury. Only $44.4 \%$ of them used utility gloves. None of the waste handlers used face mask while only $48.1 \%$ used nose mask. Some of the waste handlers did not put on face masks during burning or incineration thus exposing themselves to resulting dangerous emissions. These findings do not comply with the Occupational Safety and Health Administration OSHA, 2016 recommendations that, appropriate PPE must be used to reduce risk or worker exposure, with the employer making readily available and at no cost to employees, appropriate specialized clothing or equipment to protect exposure to blood and other potentially infectious bacteria. Our findings confirm the report of Mochungong, P.I , 2010 that the working conditions of waste pickers in Cameroon are poor. Vaccination of waste handlers against infections was low: $63 \%$ for tetanus, $51.1 \%$ for meningitis and $29.6 \%$ for hepatitis B and these vaccines were received at no cost during vaccination campaigns. This shows that other required vaccines for which there was a cost were not taken.

Waste disposal was on-site in all health facilities and waste bins were transported manually by hand-lifting to the final disposal site except in one facility where trolleys were used. Waste handlers interviewed reported waste spills during transportation as some of the bins had no lids. This is could lead to spread of infectious agents. In $26(86.7 \%)$ health facilities waste disposal was by open burning in pits and all the wastes whether segregated or not was dumped into these pits. Considering the fact that these pits were located within $400 \mathrm{~m}$ from the facility, burning produced and released smoke and dangerous emissions to the air causing air pollution and exposing people to serious health risks. Because all the wastes (wet and dry) were dumped in the pit, combustion was incomplete. Scavengers (humans and animals) were reported visiting some of these pits and thus were 
exposed to hazardous waste and infectious materials following contact or injuries and could spread infection in the community through the sale of materials recovered from the pits. Contrary to a study in Ethiopia (Debere, M.K., et al 2011) in which the disposal mechanism of health facilities was incineration, only 4 (13.4\%) facilities in our study site used incinerators. Although incinerators are alternative technology for destroying high volume medical wastes particularly when resources are limited (Chartier, Y. 2014) there is concern on its environmental impact as most of them lack air pollution control devices (Ferdowosi, A. 2010). Incinerators in our study site were locally constructed with brick and did not meet the guidelines and contributed to air pollution endangering the lives of the nearby population. Ash from these incinerators is disposed in pits and could leach into the ground polluting underground water.

\section{Limitations of study}

We did not quantify the amount of waste generated per bed per day in our study facilities. As this study was conducted during the day, staff on night duty involved in waste management could not be reached and hence could not participate in the study. Distances between some health facilities could not permit a cross section of waste handlers to be included in the study as some left the health facilities immediately after their cleaning chores in the morning.

\section{Conclusions}

Waste management practices in ours study site did not meet standard practices. There is an urgent need for proper medical waste management in Kumbo East and Kumbo West to minimize threats to human health and the environment. For this to be achieved, there is need for increased budgetary allocation to health facilities to ensure training of personnel on waste management, and purchase of PPE and required materials for safe waste handling, storage, transportation and purchase of high temperature incinerators. Regular supervision and enforcement of policy on medical waste management is paramount. This study provides baseline data that could guide policy in planning for an effective and sustainable waste management program.

\section{Declarations}

Ethics approval and consent to participate: Ethical clearance approving the study was obtained from the Catholic University of Cameroon (CATUC) Institutional Review Board, while administrative clearance was issued by the Regional Delegation of Public Health for the North West region. Authorization to access health facilities in the two districts was obtained from the District Medical Officers of Kumbo East and Kumbo West health districts. For non-public health facilities, permission was obtained from the respective authorities concerned. Study participants were required to sign an informed consent form before participating in the study. Identification codes were used instead of names of participants on questionnaires and participation was voluntary

Consent for publication: Not applicable analyzed during the current study available from the corresponding author on reasonable request.

Disclosure of conflict of interest: The authors declare they have no competing interests.

Funding: The research had no external funding. It was funded by the corresponding author from the design of the study, data collection, analysis, interpretation and the writing of the manuscript.

Acknowledgements: The authors are grateful for the useful contributions of the management and personnel of health facilities that participated in this study. We are also grateful for the contributions made by Ndong Ignatius. C, Kofete Mercy. A and Chenjoe Joseph. N.

Availability of data and materials: The datasets used and /or 


\section{Reference}

1 Awodele, O., Adeoye, A.A., Oparah, A.C. Assessment of medical waste management in seven hospitals in Lagos, Nigeria. (2016) BMC Public Health16: 269.

2 Abah, S.O., Ohimain, E.I. Healthcare waste management in Nigeria: A case study. (2011) J Public Health Epidemiol 3(3): 99-110.

3 Bassey, B.E., Benka-Coker, M.O., Aluyi, H.A.S. Characterization and management of solid medical wastes in the Federal Capital Territory, Abuja Nigeria. (2006) African Health Sci 6(1): 59-63.

4 Babanyara, Y.Y., Ibrahim, D.B., Garba, T., et al. Poor medical waste management practices and its risks to human health and the environment: a literature review. (2013)Int J Environ, Chem, Ecological, Geological and Geophysical Engineering 7(11): 780-787.

5 Chartier, Y., Emmanuel, J., Pieper, U., et al. Safe management of wastes from healthcare activities (2nd edn). (2014) World Health Organization (WHO) 308

6 Doumtsop, T.J.G. Health care waste management: a multi speed development in the sub-Saharan African region. (2014) Pan African Medical Journal 17: 305.

7 Debere, M.K., Gelaye, K.A., Alamdo, A.G., et al. Assessment of the health care waste generation rates and its management system in hospitals of Addis Ababa Ethiopia. (2011) BMC Public Health 13: 28.

8 Ferdowosi, A., Ferdosi, M., Mehrani, M.J. Incineration or autoclave? A comparative study in Isfahan hospitals waste management system. (2010) Materia Socio Medica 25(1): 48-51

9 Harhay, M.O., Halpern, S., Harnay, J.S., et al. Healthcare waste management: a neglected and growing public health problem worldwide. (2009) Trop Med Int Health 14(11): 1414-1417.

10 Hassan, M.M., Ahmed, S.A., Rahman, K.A., et al. Pattern of medical waste management: existing scenario in Dhaka City, Bangladesh. (2008) BMC Public Health 8:36.

11 Kumar, R., Somrongthong, R., Shaikh, B.T. Effectiveness of intensive healthcare waste management training model among health professional at teaching hospitals of Pakistan: a quasi-experimental study. (2015) BMC Public Health 15: 81.

12 Kumar, R., Somrongthong, R., Ahmed, J. Impact or waste management training intervention on knowledge, attitude and practices of teaching hospital workers in Pakistan. (2016) Pak J Medical Sci 32(3): 705-710.

13 Muluken, A., Haimanot, G., Mesafint, M. Healthcare waste management practices among healthcare workers in healthcare facilities of Gondar town, Northwest Ethiopia. (2013) Health Sci J 7(3): 315-326.

14 Mochungong, P.I. The plight of clinical waste pickers: evidence from the northwest region of Cameroon. (2010) J Occup Environ Health 52(2): 142-145.

15 Mochungong, P.I., Gulis, G., Sodemann, M. Hospital worker's awareness of health and environmental impacts of poor clinical waste disposal in the northwest region of Cameroon. (2010) Int J Occup Environ Health 16(1): 53-59.

16 Manga, V.E., Fortonb, O.T., Readd, A.D. Waste Management In Cameroon: A New Policy Perspective? (2008) Resources, Conservation and Recycling 52: 592-600.

17 Occupational Safety and Health Administration (OSHA). Employer Rights and Responsibilities Following a Federal OSHA Inspection. (2016) OSHA 3000-08R: 1-28 US Department of Labor.

18 Preparation of National Healthcare Waste Management Plans in sub-Saharan Countries: guidance Manual. World Health Organization (WHO) and secretariat of the Basel Convention 88.

19 Prüss, A., Giroult, E., Rushbrook, P. Safe management of wastes from healthcare activities. (1999) World Health Organization (WHO) 230.

20 Pruthvish, S., Gopinath, D., Girish, N., et al. Towards safe management of health care waste in Bangalore City. (1999) Bull World Health Organization 77(10): 862-863.

21 Ramotake, T., Basu, D. Healthcare waste management at an academic hospital: knowledge and practices of doctors and nurses. (2009) South African Medical Journal 99 (6): 444-450.

22 Solberg, K.E. Trade in medical waste causes deaths in India. (2009) Lancet 373(9669): 1067.

23 Tabash, M.I., Hussein, R.A., Mahmud, A.H., et al. Impact of an intervention program on knowledge, attitude and practice of healthcare staff regarding pharmaceutical waste management, Gaza, Palestine. (2016) Public Health 138: 127-137.

24 United Nations Environment Programme (UNEP). Minimizing hazardous wastes: A simplified Guide to the Basel Convention. France (2000) GE 04-03062.

25 Udofia, E.A., Fobil, J.N., Gulis, G. Solid waste management in Africa. (2015) African J Environ Sci Techn 9(3): 244-254.
Ommega Online Publishers

Journal Title: Journal of Environment and Health Science (JEHS)

Journal Short Name: J Environ Health Sci
Journal ISSN: 2378-6841

E-mail: environmentalscience@ommegaonline.org

Website: www.ommegaonline.org 